\title{
Solubility of Pyrene in Ternary Alcohol + Cyclohexane + Heptane Solvent Mixtures at 299.15 K
}

\author{
Ebun M. Debase and William E. Acree, J r.* \\ Department of Chemistry, University of North Texas, Denton, Texas 76203-5070
}

\begin{abstract}
Experimental solubilities are reported for pyrene dissolved in ternary 1-propanol + cycl ohexane + heptane, 2-propanol + cyclohexane + heptane, 1-butanol + cyclohexane + heptane, 2-butanol + cyclohexane + heptane, and 2-methyl-1-propanol + cyclohexane + heptane solvent mixtures at $26{ }^{\circ} \mathrm{C}$ and atmospheric pressure. Nineteen compositions were studied for each of the five solvent systems. Results of these measurements are used to test the predictive ability of the ternary solvent form of the combined NIMS/ Redlich-Kister equation. Computations showed that the model predicted the observed solubility behavior to within an overall average absolute deviation of $\sim 1.3 \%$, which is comparable to the experimental uncertainty of $\pm 1.5 \%$.
\end{abstract}

\section{Introduction}

Solid-liquid equilibrium data of organic nonelectrolyte systems are becoming increasingly important in the petroleum industry, particularly in light of present trends toward heavier feedstocks and the known carcinogenicity/ mutagenicity of many of the larger polycyclic aromatic compounds. Solubility data for a number of polycyclic aromatic hydrocarbons (i.e., anthracene and pyrene) and heteroatom polynuclear aromatics (i.e., carbazole, dibenzothiophene, and xanthene) have been published in the recent chemical literature. For a listing of references see Acree. ${ }^{1-3}$ Despite efforts by experimentalists and scientific organizations, in terms of both new experimental measurements and critically evaluated data compilations, there still exist numerous systems for which solubility data are not readily available.

In the present study pyrene solubilities have been measured in the five ternary alcohol + cyclohexane + heptane systems at $(26.0 \pm 0.1){ }^{\circ} \mathrm{C}$. Nineteen ternary compositions were studied for each of the five systems. Results of these measurements are used to test the predictive ability of expressions based upon the general mixing model used in deriving the combined NIBS/RedlichKister equation. Subsequent studies will interpret the measured pyrene solubilities using both the Mobile Order theory and the Kretschmer-Wiebe association model. Powell et al. ${ }^{4}$ and $\mathrm{McH}$ ale et al. ${ }^{5}$ showed that the latter two solution models provided reasonably accurate descriptions for the solubility behaviors of pyrene and anthracene in binary alkane + alcohol and alcohol + alcohol solvent mixtures. Neither model has been used to describe solubility in ternary solvent systems.

\section{Experimental Methods}

Pyrene (Aldrich, 98\%) was recrystallized three times from anhydrous methanol. 1-Propanol (Aldrich, 99+\%, anhydrous), 2-propanol (Aldrich, 99+\%, anhydrous), 1-butanol (Aldrich, HPLC, 99.8+\%), 2-butanol (Aldrich, 99+\%, anhydrous), 2-methyl-1-propanol (Aldrich, 99.5\%, anhy-

* Author to whom correspondence should be addressed [e-mail acree@unt.edu; fax (940) 565-4318]. drous), cyclohexane (Aldrich, HPLC, 99.9+\%), and heptane (Aldrich, HPLC, 99+\%) were stored over molecular sieves and distilled shortly before use. Gas chromatographic analysis showed solvent purities to be $99.7 \mathrm{~mol} \%$ or better. Ternary solvent mixtures were prepared by mass so that compositions could be calculated to 0.0001 mole fraction. The methods of sample equilibration and spectrophotometric analysis are discussed in an earlier paper. ${ }^{6}$ Experimental pyrene solubilities in the five alcohol + cyclohexane + heptane solvent mixtures are listed in Table 1. Numerical values represent the average of between four and eight independent determinations, with the measured values being reproducible to within $\pm 1.5 \%$.

\section{Results and Discussion}

Acree and co-workers ${ }^{7-9}$ suggested the combined NIBS/ Redlich-Kister equation for the mathematical representation of isothermal solubility data in binary solvent systems

$\ln x_{A}^{\text {sat }}=x_{B}^{o} \ln \left(x_{A}^{\text {sat }}\right)_{B}+x_{C}^{o} \ln \left(x_{A}^{s a t}\right)_{C}+x_{B}^{o} x_{C}^{o} \sum_{i=0}^{N} S_{i}\left(x_{B}^{o}-x_{C}^{o}\right)^{i}$

where $\mathrm{x}_{\mathrm{B}}{ }^{\circ}$ and $\mathrm{x}_{C}{ }^{\circ}$ refer to the initial mole fraction composition of the binary solvent calculated as if the solute were not present, and $\left(x_{A}^{\text {sat }}\right)_{i}$ denotes the measured solute solubility in pure solvent $i$. The various $S_{i}$ curve-fit parameters can be evaluated with a least-squares analysis. Equation 1 has been shown to provide very accurate mathematical representations of anthracene, pyrene, and carbazole solubilities in a large number of both complexing and noncomplexing solvent mixtures. ${ }^{1-3} \mathrm{~J}$ ouyban-Gharamaleki and coworkers ${ }^{10-13}$ successfully used the volume fraction, $\phi_{\mathrm{i}}$, modification of eq 1

$$
\ln x_{A}^{\mathrm{sat}}=\phi_{\mathrm{B}}^{\mathrm{o}} \ln \left(\mathrm{x}_{\mathrm{A}}^{\mathrm{sat}}\right)_{\mathrm{B}}+\phi_{\mathrm{C}}^{\mathrm{o}} \ln \left(\mathrm{x}_{\mathrm{A}}^{\mathrm{sat}}\right)_{\mathrm{C}}+\phi_{\mathrm{B}}^{\mathrm{o}} \phi_{\mathrm{C}}^{\mathrm{o}} \sum_{\mathrm{i}=0}^{\mathrm{N}} \mathrm{S}_{\mathrm{i}}\left(\phi_{\mathrm{B}}^{\mathrm{o}}-\right.
$$

to describe the solubility behavior of various drug molecules in binary aqueous-organic solvent mixtures. In the phar- 
1298 J ournal of Chemical and Engineering Data, Vol. 46, No. 5, 2001

Table 1. Experimental Mole Fraction Solubilities of Pyrene $\left(x_{A}^{\text {sat }}\right)$ in Ternary Alcohol (B) + Cyclohexane (C) + Heptane (D) Solvent Mixtures at 299.15 K

\begin{tabular}{|c|c|c|c|c|c|}
\hline$x_{B}^{\circ}$ & $x_{C}^{\circ}$ & $x_{A}^{\text {sat }}$ & $x_{B}^{\circ}$ & $x_{C}^{\circ}$ & $x_{A}^{\text {sat }}$ \\
\hline \multicolumn{6}{|c|}{ 1-Propanol (B) + Cyclohexane (C) + Heptane (D) } \\
\hline 0.4484 & 0.3186 & 0.01048 & 0.2510 & 0.1701 & 0.01148 \\
\hline 0.2184 & 0.6746 & 0.01218 & 0.7897 & 0.1227 & 0.00677 \\
\hline 0.3649 & 0.2561 & 0.01107 & 0.6229 & 0.2147 & 0.00868 \\
\hline 0.3407 & 0.4769 & 0.01132 & 0.1805 & 0.2221 & 0.01186 \\
\hline 0.7921 & 0.0869 & 0.00688 & 0.1497 & 0.6989 & 0.01221 \\
\hline 0.7809 & 0.1601 & 0.00682 & 0.3248 & 0.1097 & 0.01109 \\
\hline 0.2700 & 0.6594 & 0.01147 & 0.1719 & 0.4284 & 0.01214 \\
\hline 0.16 & 0.5280 & 0.01216 & 0.5488 & 0.0990 & 0.00946 \\
\hline 0.5026 & 0.4296 & 0.00984 & 0.6468 & 0.0905 & 0.00851 \\
\hline 0.608 & & & & & \\
\hline \multicolumn{6}{|c|}{ 2-Propanol (B) + Cyclohexane (C) + Heptane (D) } \\
\hline 0.4546 & 0.3148 & 0.00973 & 0.2470 & 0.1794 & 0.01115 \\
\hline 0.2110 & 0.6816 & 0.01164 & 0.7881 & 0.1220 & 0.00557 \\
\hline 0.3624 & 0.2581 & & 0.6154 & 0.2227 & 0.00777 \\
\hline 0.3384 & 0.4789 & 0.01067 & 0.1688 & 0.2202 & 0.01163 \\
\hline 0.7960 & 0.0848 & 0.00545 & 0.1583 & 0.6942 & 0.01190 \\
\hline 0.7801 & 0.1614 & 0.00557 & 0.3082 & 0.1 & 0.01085 \\
\hline & 0.6539 & & 0.1628 & 0.42 & 0.01188 \\
\hline 0.1628 & 0.5202 & 1177 & 0.5557 & 0.1025 & 0.00848 \\
\hline 0.4923 & 0.4378 & 0.00923 & 0.6309 & 0.1059 & 0.00754 \\
\hline 0.594 & 0.3366 & 0.00787 & & & \\
\hline \multicolumn{6}{|c|}{ 1-Butanol (B) + Cyclohexane (C) + Heptane (D) } \\
\hline 0.4068 & & 0.01159 & 0.2166 & 0.1775 & 0.01204 \\
\hline & 0.7 & & & 0.1391 & 0.00861 \\
\hline 0.2629 & & & 0.5759 & 0.2416 & 0.01035 \\
\hline 0.2919 & 0.5010 & 0.0 & 0.1468 & & 0.01218 \\
\hline 0.7669 & 0.0988 & & 0.1318 & & 0.01229 \\
\hline 0.7432 & 0.1875 & 0.00868 & 0.2776 & 0.1223 & 0.01194 \\
\hline 0.2360 & 0.6853 & & 0.1432 & 0.4468 & 0.01239 \\
\hline & & & 0.5024 & & 0.01 \\
\hline 0.4539 & 0.4787 & 110 & 0.5965 & 0.1094 & 0.01007 \\
\hline 0.552 & & 029 & & & \\
\hline \multicolumn{6}{|c|}{ 2-Butanol (B) + Cyclohexane (C) + Heptane (D) } \\
\hline 0.4054 & 0.3407 & 0.01124 & 0.2277 & 0.1304 & 0.01170 \\
\hline 0.1862 & 0.7051 & & 0.7576 & & \\
\hline & & & 0.5699 & 0.25 & 0.00960 \\
\hline 3041 & 5033 & 158 & 0.1508 & 0.2403 & 0.01209 \\
\hline & & & 0.13 & & 0.01 \\
\hline & & & 0.2737 & & 0.01168 \\
\hline 0.2344 & 02 & & 0.1532 & 0.4416 & 0.01220 \\
\hline & & & 0.5036 & & 0.01 \\
\hline & & & 0.5894 & 0.1077 & 0.00936 \\
\hline & & & & & \\
\hline \multicolumn{6}{|c|}{ 2-Methyl-1-propanol (B) + Cyclohexane (C) + Heptane (D) } \\
\hline 0.3977 & & & 0.2139 & 0.1780 & 0.01135 \\
\hline & & & 0.75 & & \\
\hline & & & 0.57 & 0.2 & 0.00800 \\
\hline & 0.5178 & & & & 0.01183 \\
\hline 0.76 & & & 0.13 & 0.71 & 0.01171 \\
\hline & & & 0.2834 & 0.1 & 0.01098 \\
\hline & & & 0.1369 & 0.44 & 0.01 \\
\hline 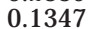 & 0.5481 & 0.01191 & 0.5026 & 0.1078 & 0.00905 \\
\hline & 0.4675 & 0.00914 & 0.5980 & 0.1033 & 0.00787 \\
\hline
\end{tabular}

maceutical industry, researchers often express the solvent composition in terms of volume fractions rather than in terms of mole fractions. In the case of structurally similar drug molecules the numerical values of the $S_{i}$ coefficients were found to be nearly constant in a given binary solvent mixture. ${ }^{10}$

For a ternary solvent system, the mathematical repre sentation takes the form of

$$
\begin{array}{r}
\ln x_{A}^{\text {sat }}=x_{B}^{o} \ln \left(x_{A}^{s a t}\right)_{B}+x_{C}^{o} \ln \left(x_{A}^{s a t}\right)_{C}+x_{D}^{o} \ln \left(x_{A}^{s a t}\right)_{D}+ \\
x_{B}^{o} x_{C}^{o} \sum_{i=0}^{r} S_{i, B C}\left(x_{B}^{o}-x_{C}^{o}\right)^{i}+x_{B}^{o} x_{D}^{o} \sum_{j=0}^{s} S_{j, B D}\left(x_{B}^{o}-x_{D}^{o}\right)^{j}+ \\
x_{C}^{o} x_{D}^{o} \sum_{k=0}^{t} S_{k, C D}\left(x_{C}^{o}-x_{D}^{o}\right)^{k}
\end{array}
$$

Recent studies have shown that eq 3 provides reasonably accurate predictions for anthracene solubilities in ternary two alkane + alcohol $^{14,15}$ and alkane + two alcohol ${ }^{16-18}$ solvent mixtures. Such systems exhibit fairly large deviations from solution ideality arising from the self-association
Table 2. Summarized Comparison between Observed Pyrene Solubilities in Ternary Alcohol + Cyclohexane + Heptane Solvent Mixtures and Predicted Values Based Upon the Combined NIMS/Redlich-Kister Equation 3

\begin{tabular}{lc}
\hline ternary solvent mixture & $\%$ dev $^{\mathrm{a}}$ \\
\hline 1-propanol (B) + cyclohexane (C) + heptane (D) & 1.63 \\
2-propanol (B) + cyclohexane (C) + heptane (D) & 1.13 \\
1-butanol (B) + cyclohexane (C) + heptane (D) & 1.00 \\
2-butanol (B) + cyclohexane (C) + heptane (D) & 1.06 \\
2-methyl-1-propanol (B) + cyclohexane (C) + heptane (D) & 1.52
\end{tabular}

a Deviation $(\%)=(100 / N) \sum\left|\left[\left(x_{A}^{\text {sat }}\right)^{\text {calcd }}-\left(x_{A}^{\text {sat }}\right)^{\text {exptl }}\right] /\left(x_{A}^{\text {sat }}\right)^{\text {expt }}\right|$ where $\mathrm{N}$ corresponds to the number of data points for each ternary system. In the present study, solubilities were determined at 19 different ternary solvent compositions.

Table 3. Comparison between Experimental Pyrene Mole Fraction Solubilities and Back-calculated Values Based upon Equation 1 for Select Sub-binary Solvent Systems

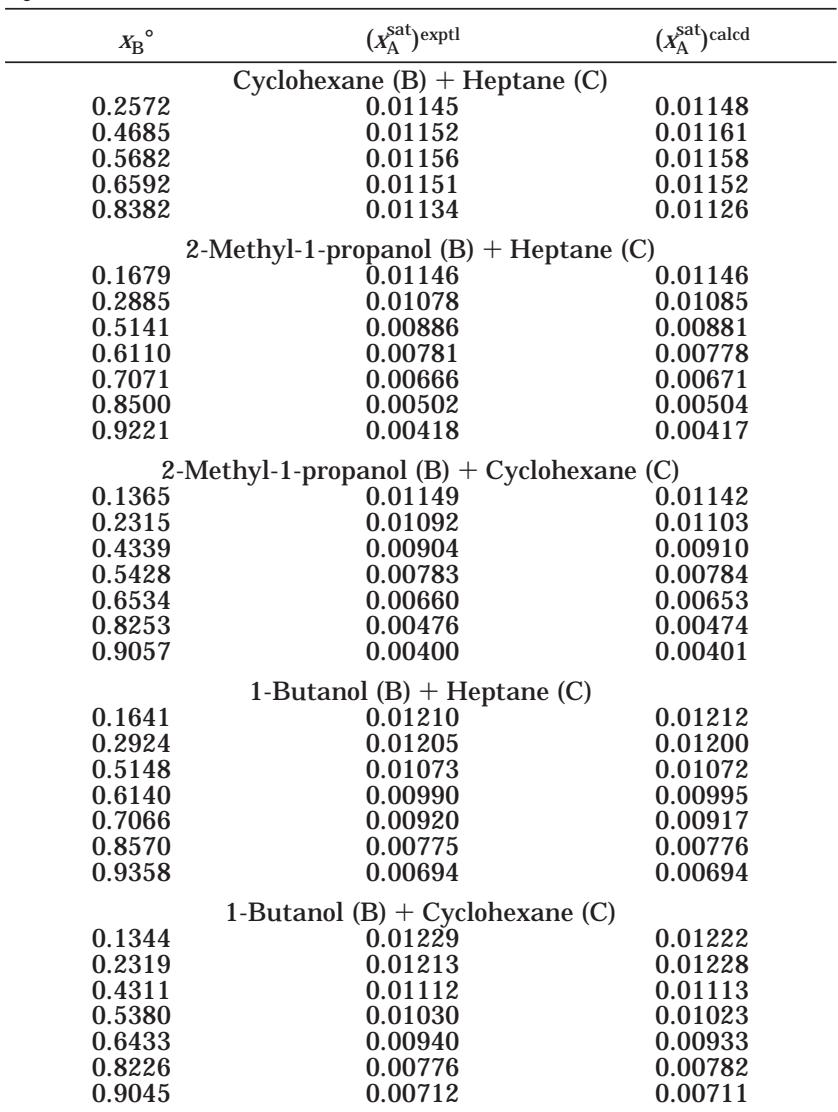

a Average absolute deviations for the individual sub-binary systems were $0.4 \%$ for cyclohexane + heptane mixtures, $0.4 \%$ for 2-methyl-1-propanol + heptane mixtures, $0.6 \%$ for 2-methyl-1propanol + cyclohexane mixtures, $0.2 \%$ for 1 -butanol + heptane mixtures, and $0.6 \%$ for 1 -butanol + cyclohexane mixtures.

of each alcohol cosolvent and in mixtures containing two alcohol cosolvents from the formation of heterogeneous hydrogen-bonded chains between dissimilar alcohol molecules.

The predictive ability of eq 3 is summarized in Table 2 for pyrene dissolved in the five alcohol + cyclohexane + heptane systems. Published papers ${ }^{19,20}$ have reported the calculated $S_{i}$ parameters for pyrene dissolved in 6 of the 11 sub-binary solvent systems. Solubility data for the remaining 5 binary solvent systems are available in the chemical literature; however, the authors did not use the combined NIBS/Redlich-Kister equation at the time the data were originally published. We have determined the numerical values of the $S_{i}$ parameters for the binary 
Table 4. Combined NIBS/Redlich-Kister Parameters Calculated from Pyrene Solubilities in the Sub-binary Solvent Systems

\begin{tabular}{cr}
\hline solvent (B) + solvent (C) & \multicolumn{1}{c}{$\mathrm{S}^{\mathrm{a}}$} \\
\hline 2-methyl-1-propanol (B) + cyclohexane (C) & 1.316 \\
& -0.427 \\
2-propanol (B) + cyclohexane (C) & 0.190 \\
& 1.726 \\
2-butanol (B) + cyclohexane (C) & 0.165 \\
& 0.372 \\
1-propanol (B) + cyclohexane (C) & 1.426 \\
& 0.064 \\
1-butanol (B) + cyclohexane (C) & 0.447 \\
& 1.396 \\
& -0.268 \\
1-propanol (B) + heptane (C) & 0.226 \\
& 0.976 \\
2-propanol (B) + heptane (C) & -0.462 \\
& 0.472 \\
& 1.383 \\
1-butanol (B) + heptane (C) & 0.202 \\
& 0.280 \\
2-butanol (C) + heptane (C) & 1.799 \\
& 0.478 \\
& 0.581 \\
2-methyl-1-propanol (B) + heptane (C) & 1.075 \\
& -0.189 \\
& 0.388 \\
cyclohexane (B) + heptane (C) & 1.583 \\
& 0.232 \\
& 0.392 \\
& 1.604 \\
& 0.151 \\
\end{tabular}

a Combined NIBS/Redlich-Kister curve-fit parameters are ordered $\mathrm{S}_{0}, \mathrm{~S}_{1}$, and $\mathrm{S}_{2}$.

cyclohexane + heptane, 1-butanol + cycl ohexane, 1-butanol + heptane, 2-methyl-1-propanol + cyclohexane and 2-methyl-1-propanol + heptane solvent systems by curve fitting the experimental pyrene mole fraction solubility data of J udy et al..$^{21}$ and Borders et al..$^{22}$ in accordance with eq 1. In the case of the four alcohol + alkane binary solvent mixtures three $S_{i}$ parameters were needed to adequately describe the experimental pyrene mole fraction solubilities. Equation 1 described the experimental data in these latter five binary solvent mixtures to better than $0.7 \%$ (see Table 3). Deviations for the remaining six sub-binary solvent mixtures are published el sewhere. ${ }^{19,20}$ Numerical values of the $S_{i}$ parameters have been given in Table 4 for convenience. Experimental molefraction solubilities in 1-propanol $\left(x_{A}^{\text {sat }}=0.00426\right), 2$-propanol $\left(x_{A}^{\text {sat }}=0.00290\right)$, 1-butanol $\left(x_{A}^{\text {sat }}=0.00622\right), 2$-butanol $\left(x_{A}^{\text {sat }}=0.00439\right), 2$-methyl-1propanol $\left(x_{A}^{\text {sat }}=0.00326\right)$, cyclohexane $\left(x_{A}^{\text {sat }}=0.01100\right)$, and heptane $\left(x_{A}^{\text {sat }}=0.01102\right)$ were also taken from the chemical literature. ${ }^{19-22}$ Examination of the numerical entries in Table 2 reveals that eq 3 predicts the solubility of pyrene to within an overall average absolute deviation of $1.3 \%$, which is comparable to the experimental uncertainty of $\pm 1.5 \%$. For the five systems studied, eq 3 was found to provide very accurate predictions of the observed solubility behavior.

\section{Literature Cited}

(1) Acree, W. E., J r. Polycyclic Aromatic Hydrocarbons in Pure and Binary Solvents; IUPAC Solubility Data Series; Oxford U niversity Press: Oxford, U.K., 1994; Vol. 54.

(2) Acree, W. E., J r. Polycyclic Aromatic Hydrocarbons: Binary Nonaqueous Systems: Part 1 (Solutes A-E); IUPAC Solubility Data Series; Oxford University Press: Oxford, U.K., 1995; Vol. 58.

(3) Acree, W. E., J r. Polycyclic Aromatic Hydrocarbons: Binary Nonaqueous Systems: Part 2 (Solutes $\mathrm{F}-\mathrm{Z}$ ); IUPAC Solubility Data Series; Oxford University Press: Oxford, U.K., 1995; Vol. 59.

(4) Powell, J . R.; McHale, M. E. R.; Kauppila, A.-S. M.; Acree, W. E., J r.; Flanders, P. H.; Varanasi, V. G.; Campbell, S. W. Prediction of Anthracene Solubility in Alcohol + Alkane Solvent Mixtures Using Binary Alcohol + Alkane VLE Data. Comparison of Kretschmer-Wiebe and Mobile Order Models. Fluid Phase Equilib. 1994, 134, 185-200.

(5) McHale, M. E. R.; Zvaigzne, A. I.; Powell, J . R.; Kauppila, A.-S. M.; Acree, W. E., J r.; Campbell, S. W. Thermochemical Investigations of Hydrogen-Bonded Solutions. Part 9. Comparison of Mobile Order Theory and the Kretschmer-Wiebe Association Model for Predicting Pyrene Solubilities in Binary Alcohol + Alcohol Solvent Mixtures. Phys. Chem. Liq. 1996, 32, 67-87.

(6) McHale, M. E. R.; Coym, K. S.; Fletcher, K. A.; Acree, W. E., J r. Solubility of Pyrene in Binary Alcohol + 2-Methyl-2-butanol Solvent Mixtures at 299.2 K. J . Chem. Eng. Data 1997, 42, 511513.

(7) Acree, W. E., J r. Mathematical Representation of Thermodynamic Properties. Part 2. Derivation of the Combined Nearly I deal Binary Solvent (NIBS)/Redlich-Kister Mathematical Representation from a Two-Body and Three-Body Interactional Mixing Model. Thermochim. Acta 1992, 198, 71-79.

(8) Acree, W. E., J r.; Zvaigzne, A. I. Thermodynamic Properties of Nonelectrolyte Solutions. Part 4. Estimation and Mathematical Representation of Solute Activity Coefficients and Solubilities in Binary Solvents Using the NIBS and Modified Wilson Equations. Thermochim. Acta 1991, 178, 151-167.

(9) Acree, W. E., J r.; McCargar, J . W.; Zvaigzne, A. I.; Teng, I.-L. Mathematical Representation of Thermodynamic Properties. Carbazole Solubilities in Binary Alkane + Dibutyl Ether and Alkane + Tetrahydropyran Solvent Mixtures. Phys. Chem. Liq. 1991, 23, 27-35.

(10) J ouyban-Gharamaleki, A.; Clark, B. J .; Acree, W. E., J r. Prediction of Drug Solubility in Ternary Solvent Mixture. Drug Dev. Ind. Pharm. 2000, 26, 971-973.

(11) J ouyban-Gharamaleki, A.; Acree, W. E., J r. Comparison of Models for Describing Multiple Peaks in Solubility Profiles. Int. J . Pharm. 1998, 167, 177-182.

(12) J ouyban-Gharamaleki, A.; Hanaee, J . A Novel Method for Improvement of the CNIBS/R-K Equation. Int. J . Pharm. 1997, 154, 243-245.

(13) J ouyban-Gharamaleki, A.; Barzegar-J alali, M.; Acree, W. E., J r. Solubility Correlation of Structurally Related Drugs in Binary Solvent Mixtures. Int. J . Pharm. 1998, 166, 205-209.

(14) Deng, T.; Acree, W. E., J r. Solubility of Anthracene in Ternary Propanol + 2,2,4-Trimethylpentane + Cyclohexane and Butanol $+2,2,4-$ Trimethylpentane + Cyclohexane Solvent Mixtures. J . Chem. Eng. Data 1998, 43, 1059-1061.

(15) Deng, T.; Hernández, C. E.; Roy, L. E.; Acree, W. E., J r. Solubility of Anthracene in Ternary (Propanol + Heptane + Cyclohexane) and (Butanol + Heptane + Cyclohexane) Solvent Mixtures. J. Chem. Thermodyn. 1999, 31, 205-210.

(16) Deng, T.; Acree, W. E., J r. Solubility of Anthracene in Ternary Propanol + Butanol + Cyclohexane Solvent Mixtures. J . Chem. Eng. Data 1998, 43, 1062-1064.

(17) Deng, T.; Childress, S. D.; De Fina, K. M.; Sharp, T. L.; Acree W. E., J r. Solubility of Anthracene in Ternary Propanol + Butanol $+2,2,4-T r i m e t h y l p e n t a n e$ Solvent Mixtures. J . Chem. Eng. Data 1998, 43, 1065-1067.

(18) Deng, T.; Childress, S. D.; De Fina, K. M.; Acree, W. E., J r. Solubility of Anthracene in Ternary Propanol + Butanol + HeptaneSolvent Mixtures. Chem. Eng. Commun. 1999, 172, 217224.

(19) Zvaigzne, A. I.; Acree, W. E., J r. Solubility of Pyrene in Binary Alkane + 1-Propanol and Alkane + 2-Propanol Solvent Mixtures. J. Chem. Eng. Data 1993, 38, 393-395.

(20) Hernández, C. E.; Coym, K. S.; Roy, L. E.; Powell, J . R.; Acree W. E., J r. Solubility of Pyrene in Binary (Alkane + 2-Butanol) Solvent Mixutres. J. Chem. Thermodyn. 1998, 30, 37-42.

(21) J udy, C. L.; Pontikos, N. M.; Acree, W. E., J r. Solubility of Pyrene in Binary Solvent Mixtures Containing Cyclohexane. J. Chem. Eng. Data 1987, 32, 60-62.

(22) Borders, T. L.; McHale, M. E. R.; Powell, J . R.; Coym, K. S.; Hernández, C. E.; Roy, L. E.; Acree, W. E., J r.; Williams, C. D. Campbell, S. W. Thermodynamics of Mobile Order Theory: Comparison of Experimental and Predicted Anthracene and Pyrene Solubilities in Binary Alkane + Alcohol Solvent Mixtures. Fluid Phase Equilib. 1998, 146, 207-221.

Received for review March 6, 2001. Accepted J une 7, 2001.

J E0100692 